\title{
In vivo Comparison of the Regulation of Releasable Dopamine in the Caudate Nucleus and the Nucleus Accumbens of the Rat Brain
}

\author{
Werner G. Kuhr, James C. Bigelow, and R. Mark Wightman \\ Department of Chemistry, Indiana University, Bloomington, Indiana 47405
}

In vivo voltammetry has been used to measure the release of dopamine evoked by electrical stimulation of the medial forebrain bundle (MFB). Simultaneous measurements have been made with voltammetric-sensing electrodes ipsilateral to the stimulating electrode in the nucelus accumbens and the caudate nucleus of the anesthetized rat. During the stimulation, the species observed in both regions is voltammetrically identical to dopamine. Further evidence for the identity of dopamine is provided by anatomical, physiological, pharmacological, and postmortem data. Postmortem analysis of these brain regions after a single stimulation demonstrates that dopamine levels are unchanged, while dihydroxyphenylacetic acid (DOPAC) levels are increased in both regions. Systemic application of synthesis inhibitors results in a decrease in evoked release for each brain region. Amfonelic acid results in a restoration of stimulated release after synthesis inhibition. Evoked release is affected differently by pargyline in the two brain regions. The evoked release of dopamine is significantly elevated in the nucleus accumbens as a result of pargyline administration, but similar effects are not seen in the caudate nucleus. Tissue levels of dopamine are increased in both brain regions by pargyline, but the increase is significantly greater in the accumbens. Electrolytic lesions of the striatonigral pathway or systemic administration of picrotoxin eliminates the pargyline-induced difference in evoked release of dopamine. Amphetamine causes a reduction in stimulated release in the caudate nucleus with little effect on that observed in the nucleus accumbens. Administration of pargyline prior to amphetamine results in a diminution of release in both brain regions. Taken together, these data indicate that different factors affect regulation of the releasable pool of dopamine in the nucleus accumbens and caudate nucleus.

Several major dopaminergic systems exist in the mammalian brain, including the nigrostriatal and mesolimbic systems. It is known that the mesolimbic system plays an important role in the regulation of normal brain function, and this role is distinct from that played by the nigrostriatal dopamine pathway (Mogenson and Yin, 1981; White and Wang, 1982). It has been shown by unit-recording techniques that these two regions respond in different manners to pharmacological stimuli thought to affect dopaminergic neurons (Rebec and Zimmerman, 1980; Reynolds et al., 1981). The behavioral responses elicited by electrical stimulation of these two pathways differ (van der Heyden, 1984). Lesions of the two regions also produce different behavioral responses (Kelly and Moore, 1976; Pycock and Marsden, 1978). Furthermore, anatomical differences have been shown at an ultrastructural level (Bouyer et al., 1984). A rec-

Received June 10, 1985; revised Oct. 7, 1985; accepted Oct. 10, 1985.

This work was supported by a grant from the National Science Foundation, Neurobiology Section.

Correspondence should be addressed to R. M. Wightman, Department of Chemistry, Indiana University, Bloomington, IN 47405.

Copyright @ 1986 Society for Neuroscience $0270-6474 / 86 / 040974-09 \$ 02.00 / 0$ ognized major difference of these two brain regions is the function of neuronal feedback loops for the two pathways. The striatonigral pathway (Javoy et al., 1972) plays a large regulatory role, while considerable evidence exists that a corresponding regulation does not exist for the nucleus accumbens (Wang, $1981 \mathrm{a}, \mathrm{b})$. However, it is less clear whether different local factors exist that regulate dopamine release in these two brain regions.

Electrical stimulation of the medial forebrain bundle (MFB) has been used extensively to activate dopamine neurons for studying behavior mediated by dopamine, or for examining changes in levels of dopamine or its metabolites (for a review, see Korf, 1979). We have previously shown that stimulation of this neuronal tract causes a release of dopamine that can be monitored with a carbon fiber voltammetric electrode implanted at the caudate nucleus (Ewing and Wightman, 1984; Ewing et al., 1983; Kuhr et al., 1984). Dopamine has been identified as the compound detected in the caudate nucleus by voltammetric, anatomical, physiological, pharmacological, and postmortem data. The dopamine that is observed in the extracellular fluid of the caudate nucleus as a result of evoked release is related to the amount of dopamine in the releasable pool (Ewing et al., 1983). For example, synthesis inhibition results in a decrease of dopamine observed during stimulation, while enhancement of dopamine synthesis has an opposite effect (Stamford et al., 1985). Thus, the combination of in vivo voltammetry, which enables identification of dopamine, with electrical stimulation of neuronal processes provides an ideal way to examine the factors that affect the dopamine releasable pool.

In this work, we present data that demonstrate the similarities and differences of the evoked release of dopamine in the caudate nucleus and nucleus accumbens following electrical stimulation of the MFB. Evidence will be presented that establishes that dopamine is the major substance detected in the nucleus accumbens. As will be shown, evoked release of dopamine suggests that the functional stores of this neurotransmitter are regulated in different ways in the two brain regions. A major difference in regulation will be shown to occur via monoamine oxidase (MAO).

\section{Materials and Methods}

\section{Stimulated dopamine release}

The surgical procedure, stimulation parameters, and electrodes and apparatus have been described in detail in a previous publication (Kuhr et al., 1984). Male Sprague-Dawley rats were anesthetized with chloral hydrate and placed in a stereotaxic frame. Disk-shaped electrodes (diameter $=12 \mu \mathrm{m}$ ) were fabricatcd from carbon fibers sealed in glass capillary tubes. Two of these microvoltammetric electrodes, mounted on the same stereotaxic holder, were lowered into the caudate nucleus and nucleus accumbens at the following stereotaxic coordinates: AP, 3.5, $2.5 ; \mathrm{L}, 1.5 ; \mathrm{V},-6.2,-4.0 \mathrm{~mm}$, as measured from bregma and dura (Pelligrino and Cushmann, 1967). Placement was verified by histology. The electrodes were connected to a multielectrode potentiostat. Data acquisition and control were handled by a microcomputer (Ewing et al., 


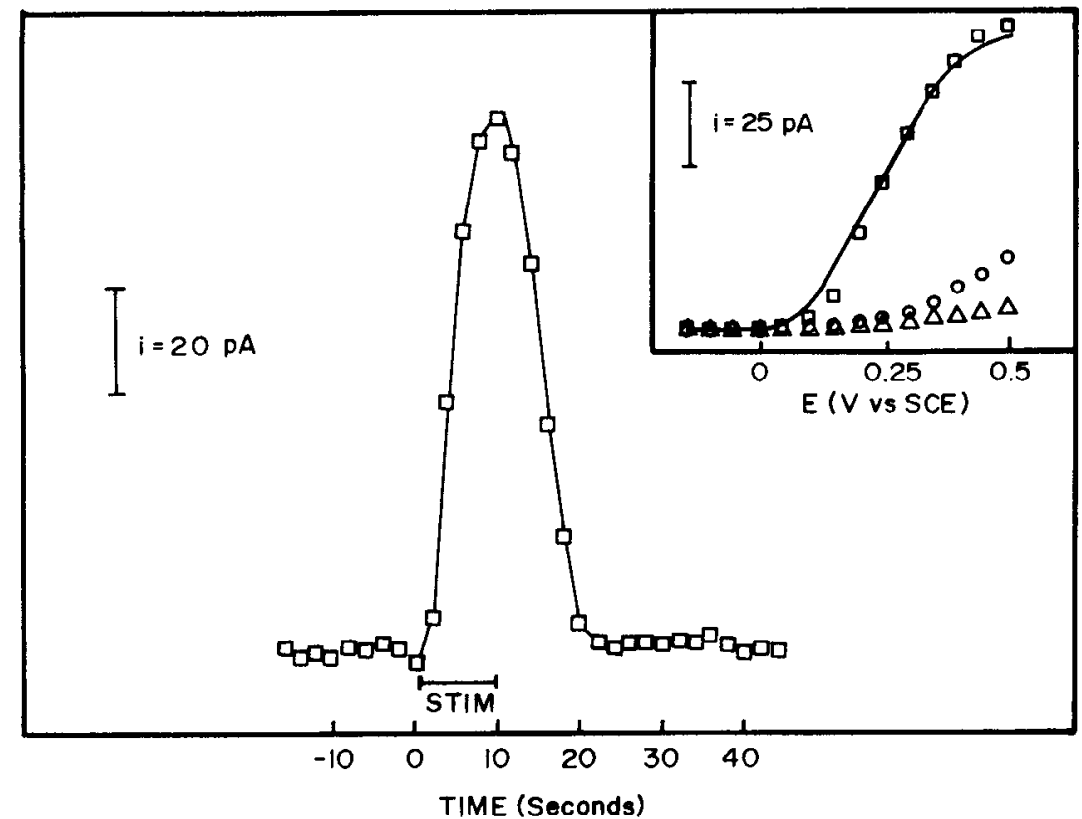

Figure 1. Response of a microvoltammetric disk electrode placed in the nucleus accumbens to a $10 \mathrm{sec}, 60 \mathrm{~Hz}$, $80 \mu \mathrm{A}$ sinusoidal stimulation of the MFB. Time-course data were obtained with repetitive chronoamperometry ( $92 \mathrm{msec}$ pulse, -0.2 to $0.5 \mathrm{~V}$ vs standard calomel electrode (SCE), repeated every $2 \mathrm{sec}$ ). Insert, Subtracted normal pulse voltammograms obtained in vivo at the peak of stimulation (solid line) and in vitro following the in vivo experiment (squares, $40 \mu \mathrm{M}$ DA; circles, $200 \mu \mathrm{M} \mathrm{AA}$; triangles, $40 \mu \mathrm{M}$ DOPAC). Scans were obtained every $4 \sec (-0.2$ to $+0.5 \mathrm{~V}$ vs SCE, $250 \mathrm{mV} / \mathrm{sec})$; the in vivo result was obtained by subtraction of a scan before the stimulation from a scan at the peak of stimulation.
1982). Voltammograms were obtained with normal pulse, backstepcorrected voltammetry (Ewing et al., 1981). This technique has been previously shown to give distinct voltammograms for catecholamines (Kovach et al., 1984). However, the techique is not sufficiently sensitive to detect the basal concentration of catecholamines in extracellular fluid (Ewing et al., 1982, 1983).

A bipolar-stimulating electrode (Plastic Products Co., Roanoke, VA; tip spacing equals $0.65 \mathrm{~mm}$ ) was used to stimulate the MFB. The stimulating electrode was placed $2.2 \mathrm{~mm}$ posterior to bregma and $1.6 \mathrm{~mm}$ lateral to the central suture. Location of the MFB was accomplished as previously described, and the placement of the tip of the stimulating electrode was adjusted for maximal response in each region (Kuhr et al., 1984). Except as noted, stimulations consisted of sinusoidal $60 \mathrm{~Hz}$, $80 \mu \mathrm{A}$ rms current applied for $10 \mathrm{sec}$ at $20 \mathrm{~min}$ intervals.

\section{Postmortem tissue analysis}

Rats were killed and their brains were quickly removed and placed in ice-cold saline. The nucleus accumbens was dissected according to the procedure of Horn et al. (1974). Special effort was taken to remove all striated tissue from the nucleus accumbens portion so that cross-contamination would be minimal. The caudate nucleus was dissected from the same brain slice used to obtain the nucleus accumbens. The striated tisuse dorsal to the accumbens was dissected from contaminating tissue. The tissue samples were weighed and placed in ice-cold $0.1 \mathrm{M}$ perchlorate. Homogenization was accomplished by sonicating until dissolution was complete. Samples were frozen at $-8^{\circ} \mathrm{C}$ for subsequent liquid chromatographic analysis with electrochemical detection. The liquid chromatographic procedure has been described previously (Kuhr et al., 1984); it cmploys a reversed-phase, C-18 column (Biophase, Bioanalytical Systems, West Lafayette, IN). The mobile phase (pH 2.8) contained $0.1 \mathrm{M}$ citrate and $1.1 \mathrm{~mm}$ sodium octylsulfate. Methanol was used to adjust the retention time of dopamine to approximately 12 min (approximately 10\% methanol by volume). This procedure allowed for the simultaneous determination of dihydroxyphenylalanine (DOPA), norepinephrine, dopamine, dihydroxyphenylacetic acid (DOPAC), homovanillic acid (HVA), and various other catecholamine metabolites.

\section{Drug administration}

Drugs were administered intraperitoneally through the use of an indwelling catheter. Injections were made $10 \mathrm{~min}$ prior to the fourth stimulation and were $0.1 \mathrm{ml}$ per $100 \mathrm{gm}$ body weight, with the exception of pargyline, which was $1 \mathrm{ml}$ per $100 \mathrm{gm}$. Amphetamine sulfate, benztropine, NSD-1015, haloperidol, pargyline, and $\alpha$-methyl-p-tyrosine were dissolved in $0.9 \%$ saline. Amfonelic acid was dissolved in 9:1 propylene glycol:0.1 $\mathrm{M} \mathrm{Na}_{2} \mathrm{CO}_{3}$. FLA-63 was dissolved in 95\% ethanol and diluted 10 -fold with $0.9 \%$ saline. Animals were anesthetized for the duration of the in vivo measurements by booster injections of chloral hydrate.

\section{Electrolytic lesions}

Lesions of the crus cerebri were made in chloral hydrate anesthetized animals by placing a bipolar-stimulating electrode (Plastic Products; tip spacing $0.64 \mathrm{~mm}$ ) at the stereotaxic coordinates (relative to bregma and dura) AP, 4.1; L , 2.4; and V, -9.0 (during lesions, the upper incisor bar was placed at the level of the interaural line). A $2 \mathrm{~mA}$ DC current was passed for $15 \mathrm{sec}$ at constant current, using a Grass Model DCLM5 lesion maker (Grass Instruments, Quincy, MA). Animals were allowed to recuperate for one week prior to expcrimcntation. Lesions were verified histologically after in vivo experimentation. Postmortem analysis of lesioned animals showed increased levels of DOPAC and HVA in the striatum, with no change in dopamine levels, in agreement with previous reports (Di Chiara et al., 1977).

\section{Monoamine oxidase assay}

MAO B activity was assayed, using a modification of Nissinen's (1984) procedure. For each assay, striatal or accumbens tissue was dissected from a male Sprague-Dawley rat, as described above. The pooled tissue samples from each region were homogenized in $2 \mathrm{ml}$ of ice-cold $6 \mathrm{mM}$ HEPES ( $\mathrm{pH} 8.1$ ) with a Teflon-to-glass homogenizer (15 strokes, 230 $\mathrm{rpm}$ ) and placed on ice for $1 / 2 \mathrm{hr}$. The assay incubation medium contained $0.8 \mathrm{ml}$ physiological buffer, $0.1 \mathrm{ml}$ substrate (benzylamine), and $0.1 \mathrm{ml}$ homugenate. The assay was initiated by the addition of the homogenate, incubated for one-half hour, and quenched with $50 \mu \mathrm{l}$ of $5 \mathrm{~N}$ perchloric acid. Substrate was added in five concentrations ranging between 50 and $500 \mu \mathrm{M}$ benzylamine.

The metabolic product of benzylamine-benzaldehyde-was assayed with liquid chromatography with UV detection (Altex Model 330, fixed wavelength $254 \mathrm{~nm}$ ). The separation was accomplished using a reversedphase, C-18 column (Biophase ODS; Bioanalytical Systems Inc.) and a mobile phàse consisting of $0.1 \mathrm{M}$ citric acid, $0.055 \mathrm{M}$ sodium acetate (pH 4.0) with $50 \%$ methanol. A $50 \mu \mathrm{l}$ injection was employed, and a flow rate of $1 \mathrm{ml} / \mathrm{min}$ was used. Kinetic data were obtained by the method of Wilkinson (1961), and the enzymatic velocity was normalized to the protein content of each sample (protein was determined by the Lowry method).

\section{Results}

\section{Release observed during electrical stimulation}

Application of an alternating current to the MFB produces a rapid increase in the oxidation current meaured at electrodes ipsilateral to the stimulation, and placed in the nucleus accumbens and the caudate nucleus. Stimulation of regions dorsal or ventral to the MFB results in no change of the electrochemical signal in either region (Kuhr et al., 1984). The oxidation current 
Table 1. Characteristics of the stimulated release of dopamine in the caudate nucleus and nucleus accumbens

\begin{tabular}{|c|c|c|c|}
\hline \multirow[b]{2}{*}{ Stimulation condition } & \multirow[b]{2}{*}{$n$} & \multicolumn{2}{|l|}{ Response } \\
\hline & & $\begin{array}{l}\text { Nucleus } \\
\text { accumbens }\end{array}$ & $\begin{array}{l}\text { Caudate } \\
\text { nucleus }\end{array}$ \\
\hline Frequency for maximum release & 3 & $60 \mathrm{~Hz}$ & $60 \mathrm{~Hz}$ \\
\hline Threshold for release & 3 & $25 \mu \mathrm{A}$ & $25 \mu \mathrm{A}$ \\
\hline Current required for maximum release & 3 & $70 \mu \mathrm{A}$ & $60 \mu \mathrm{A}$ \\
\hline Maximum duration of release & 6 & $10 \mathrm{sec}$ & $10 \mathrm{sec}$ \\
\hline Maximum amount of DA released & 15 & $67 \pm 12 \mu \mathrm{M}$ & $53 \pm 5 \mu \mathrm{M}$ \\
\hline$\%$ Release $30 \mathrm{~min}$ after $150 \mathrm{mg} / \mathrm{kg} \alpha$-methyl-p-tyrosine & 4 & $43 \pm 4.9$ & $46 \pm 5.3$ \\
\hline$\%$ Release $50 \mathrm{~min}$ after $150 \mathrm{mg} / \mathrm{kg}$ NSD- 1015 & 4 & $28 \pm 15$ & $32 \pm 6.8$ \\
\hline$\%$ Release $170 \mathrm{~min}$ after $1 \mathrm{mg} / \mathrm{kg}$ reserpine & 4 & $63 \pm 11$ & $57 \pm 3$ \\
\hline$\%$ Release $10 \mathrm{~min}$ after $1 \mathrm{mg} / \mathrm{kg}$ haloperidol & 4 & $122 \pm 3$ & $123 \pm 9$ \\
\hline$\%$ Release $10 \mathrm{~min}$ after $25 \mathrm{mg} / \mathrm{kg}$ benztropine & 3 & $92 \pm 3.8$ & $91 \pm 6.2$ \\
\hline$K_{\mathrm{m}}$ for $\mathrm{MAO}$ & 3 & $87 \pm 10 \mu \mathrm{M}$ & $82 \pm 11 \mu \mathrm{M}$ \\
\hline$V_{\max }$ for $\mathrm{MAO}(\mathrm{pmol} / \mathrm{min} / \mathrm{mg})$ & 3 & $990 \pm 140$ & $930 \pm 120$ \\
\hline
\end{tabular}

All data for the nucleus accumbens are statistically identical to those obtained in the caudate nucleus $(p>0.05$; twotailed Student's $t$ test).

continues to increase until stimulation is ended, at which point the observed response decays rapidly back to baseline (Fig. 1). The release in the accumbens is of similar magnitude (vide infra) and duration as that seen in the caudate nucleus. The half-widths of the evoked release curves are slightly different in the two regions $(9.6 \pm 0.5 \mathrm{sec}$ for the accumbens, $8.2 \pm 0.3 \mathrm{sec}$ for the caudate, $n=6)$.

\section{Voltammetric identification of the released species}

A voltammogram from a microvoltammetric disk electrode placed in the nucleus accumbens is shown in Figure 1. The subtraction of a scan taken at the peak of stimulation from one taken immediately before the stimulation produces a voltammogram of the species released, and it is identical to that obtained for dopamine in physiological buffer after the in vivo experiment. Systemic application of FLA-63 $(10 \mathrm{mg} / \mathrm{kg}$, a dopamine- $\beta$-hydroxylase inhibitor), docs not significantly alter the observed result $(n=4, p>0.05)$.

\section{Effect of stimulation parameters on evoked release}

The amplitude of the observed release in the nucleus accumbens has becn cxamincd as a function of frequency, amplitude, and duration of the applied stimulus, with results similar to those previously reported for the caudate nucleus (Kuhr et al., 1984). Frequencies between 30 and $195 \mathrm{~Hz}$ produce an observable response in both regions, whereas frequencies above $240 \mathrm{~Hz}$ or less than $30 \mathrm{~Hz}$ produce no observable response. We found that a maximum in the observed release occurs at $60 \mathrm{~Hz}$ in both regions ( $n=3$ for each). These data, and other results from the two regions, are summarized in Table 1.

The influence of the amplitude of the stimulation current has been examined with a frequency of $60 \mathrm{~Hz}(n=3)$. A threshold value of approximately $25 \mu \mathrm{A}$ is necessary to evoke any significant response. Above this value, the response increases linearly with increasing stimulation current until a maximum release is obtained at $60 \mu \mathrm{A}$. At higher stimulation currents, the observed response is independent of the amplitude. Calibration of the electrode in dopamine solutions after the in vivo experiment indicates that the concentration of dopamine at the peak of a $10 \mathrm{sec}, 60 \mathrm{~Hz}, 80 \mu \mathrm{A}$ stimulation is $67 \pm 12 \mu \mathrm{M}(n=15)$ in the nucleus accumbens and $53 \pm 5 \mu \mathrm{M}(n=15)$ in the caudate nucleus.

The effect of the duration of the stimulation on release has been examined by varying the length of a $60 \mathrm{~Hz}, 80 \mu \mathrm{A}$ stimulus between 10 and $30 \mathrm{sec}$. Maximum release is observed $10 \mathrm{sec}$ after the initiation of the stimulation in both regions, regardless of the duration of the stimulation ( $n=6$ for each).

\section{Postmortem evidence}

Analysis of the tissue levels of dopamine and its metabolites in the nucleus accumbens following a single electrical stimulation indicates that dopamine levels are unaffected by the stimulation (Table 2). The amount of DOPAC, however, is increased after such a stimulation. In the accumbens, the amount of DOPAC formed as a result of a single stimulation is $18.7 \pm 3.4 \%(n=$ 6 ) of the dopamine content, while in the caudate nucleus the amount formed is $13.2 \pm 1.8 \%(n=6)$.

\section{Effect of synthesis inhibition}

Inhibition of dopamine synthesis by systemic administration of $\alpha$-methyl- $p$-tyrosinc $(200 \mathrm{mg} / \mathrm{kg}$ ) results in a diminution of dopamine release in the nucleus accumbens $(n=4)$ that is identical to that observed in the caudate nucleus (Ewing et al., 1983). Similar temporal profiles are observed following 3-hydroxybenzylhydrazine (NSD-1015;150 mg/kg) in the caudate nucleus and nucleus accumbens ( $n=4$; Fig. 2 ). With both drugs, the amount of stimulated release is reduced within $2 \mathrm{hr}$ to less than $5 \%$ of the predrug levels in both regions.

Postmortem analysis after NSD-1015 and repetitive electrical stimulations shows that the total tissue content of dopamine is diminished in both areas. In the nucleus accumbens, dopamine levels are $54 \pm 3.8 \%(n=5)$ of control, while in the caudate nucleus the amount of dopamine remaining is $67 \pm 6.0 \%(n=$ 5 ) of a control treated with NSD-1015 (Table 2).

\section{Effect of pharmacological agents}

Reserpine ( $1 \mathrm{mg} / \mathrm{kg}$ ), known to inhibit vesicular uptake of catecholamines (Scherman and Henry, 1980), diminishes the stimulated release of dopamine from the accumbens in a manner similar to that observed in the caudate nucleus $(n=4$; Table 1 ; Kuhr et al., 1985). Haloperidol (1.0 mg/kg), a dopamine-receptor antagonist, causes an increase in evoked release of $22 \pm 3 \%$ in the nucleus accumbens and $23 \pm 9 \%$ in the caudate nucleus $(n=4)$. Benztropine $(25 \mathrm{mg} / \mathrm{kg})$, an inhibitor of neuronal uptake of dopamine (Hunt et al., 1979), does not significantly change the time course of dopamine disappearance in the accumbens, and it has little effect on the amount of stimulated release $(n=$ 4 ; Table 1), in accord with previously published results regarding 
Table 2. Effects of electrical stimulation of the MFB on the levels of DA and DOPAC in the caudate nucleus and the nucleus accumbens

\begin{tabular}{|c|c|c|c|c|c|}
\hline \multirow[b]{2}{*}{ Treatment } & \multirow[b]{2}{*}{$n$} & \multicolumn{2}{|c|}{$\begin{array}{l}\text { Dopamine } \\
\text { (pmol/mg) }\end{array}$} & \multicolumn{2}{|l|}{$\begin{array}{l}\text { DOPAC } \\
(\mathrm{pmol} / \mathrm{mg})\end{array}$} \\
\hline & & Caudate & $\begin{array}{l}\text { Accum- } \\
\text { bens }\end{array}$ & Caudate & $\begin{array}{l}\text { Accum- } \\
\text { bens }\end{array}$ \\
\hline Control $^{a}$ & 6 & $98 \pm 4$ & $53 \pm 2$ & $12 \pm 0.6$ & $5.7 \pm 0.5$ \\
\hline Stimulation $^{a}$ & 6 & $90 \pm 5$ & $55 \pm 3$ & $25 \pm 1.6^{b}$ & $16 \pm 1.7^{b}$ \\
\hline NSD-1015/sham & 3 & $104 \pm 7$ & $54 \pm 0.7$ & $10 \pm 0.8$ & $13 \pm 2.7$ \\
\hline NSD- $1015 /$ stim $^{c}$ & 5 & $69 \pm 4^{d}$ & $29 \pm 2.0^{d}$ & $5.5 \pm 0.8^{d}$ & $3.9 \pm 0.8^{a}$ \\
\hline
\end{tabular}

Values given are as $\mathrm{pmol} / \mathrm{mg}$ tissue, errors are SEM.

${ }^{a}$ Anesthetized rats were electrically stimulated ( $10 \mathrm{sec}, 80 \mu \mathrm{A}, 60 \mathrm{~Hz}$, sinusoidal) and killed $8 \mathrm{~min}$ after the stimulation. Control animals were anesthetized, electrodes were implanted, but no stimulation was performed.

${ }^{b}$ Different from control, $p<0.001$; two-tailed Student's $t$ test.

'Anesthetized rats were treated with NSD-1015 $(150 \mathrm{mg} / \mathrm{kg}) 78 \mathrm{~min}$ before death. Stim animals received a $10 \sec 80 \mu \mathrm{A}, 60 \mathrm{~Hz}$ sinusoidal stimulation $8 \mathrm{~min}$ before death. Sham animals were anesthetized, electrodes were implanted, but no stimulation was performed.

${ }^{d}$ Different from sham, $p<0.05$; two-tailed Student's $t$ test.

the caudate nucleus (Ewing and Wightman, 1984; Stamford et al., 1985).

Amfonelic acid has been shown to cause an increase in the amount of evoked release of dopamine in the caudate nucleus, even following synthesis inhibition by $\alpha$-methyl-p-tryosine (Ewing et al., 1983). Administration of amfonelic acid $(2.5 \mathrm{mg} / \mathrm{kg})$ after diminution of dopamine-stimulated release by $\alpha$-methyl$p$-tyrosine also results in a restoration of release in the nucleus accumbens. However, the amount of restored release in the accumbens $(43 \pm 6.9 \%)$ is significantly less than that in the caudate nucleus $(68 \pm 6.1 \%, n=3, p<0.05)$.

\section{Effect of pargyline on evoked release}

Pargyline $(75 \mathrm{mg} / \mathrm{kg})$, an inhibitor of both forms of monoamine oxidase (Fekete et al., 1979), has a greatly different effect on the stimulated release of dopamine in the two brain regions examined (Fig. 3). Evoked release of dopamine is unchanged in the nucleus accumbens $10 \mathrm{~min}$ after drug administration $(n=$ $4, p>0.05$ ), but a decrease in the released amount is observed in the caudate nucleus $(64 \pm 7.9 \%, n=4, p<0.001)$. Thirty minutes after pargyline, the stimulated release of dopamine is significantly above predrug levels in the accumbens (133 \pm $12.6 \%, n=4, p<0.05$ ) while dopamine release in the striatum is still beneath control levels $(85 \pm 5.0 \%, n=4, p<0.05)$.

Tissue levels of dopamine also have been examined after pargyline (Table 3 ). In both regions, tissue levels are increased $40 \mathrm{~min}$ after pargyline administration. This effect is seen whether or not anesthesia is employed. The percentage increase of dopamine following pargyline, however, is much higher in the accumbens $[182 \pm 17.9 \%$ in the accumbens vs $131 \pm 12.9 \%$ in the caudate $(n=4, p<0.05)]$.

\section{Alteration of the effect of pargyline}

Electrolytic lesions of the crus cerebri, which contains the fibers of the striatonigral pathway, can be accomplished without causing damage to the nigrostriatal pathway (Tulloch et al., 1978). These lesions, which eliminate the major feedback pathway for this system, do not affect stimulated release in the caudate nucleus. However, these lesions do eliminate the differential effect of pargyline on stimulated release (Fig. 4). Increased release in the caudate nucleus is observed in lesioned animals after pargyline ( $154 \pm 23 \%, n=4, p<0.001$ ), as is normally observed in the accumbens.

Since GABA is a neurotransmitter in the striatonigral pathway (Javoy and Glowinski, 1971), the effect of picrotoxin, a GABA antagonist, was examined in animals that were stimulated and



Figure 2. Inhibition of dopamine synthesis diminishes the stimulated release of dopamine in the nucleus accumbens and the caudate nucleus of an anesthetized rat. Each trace represents the amount of dopamine released as a result of a $10 \mathrm{sec}, 80 \mu \mathrm{A}, 60 \mathrm{~Hz}$ electrical stimulation of the MFB in a single animal. Data were obtained with repetitive chronoamperometry $(92 \mathrm{msec}$ step from -0.2 to $+0.5 \mathrm{~V}$ vs SCE, repeated every $2 \mathrm{sec})$, stimulations were repeated every $20 \mathrm{~min}$. NSD-1015 (150 $\mathrm{mg} / \mathrm{kg}$ ) was administered $10 \mathrm{~min}$ after the third stimulation (indicated by the arrow). The response of the electrode was calibrated in solution following the in vivo experiment in order to calculate the concentration of dopamine released during the stimulation.

administcred pargylinc. Picrotoxin pretreatment results in an increase of stimulated release in the caudate nucleus following pargyline $(121 \pm 5.6 \%, n=4, p<0.01$; Fig. 4$)$, whereas the effects of pargyline are unchanged in the nucleus accumbens with picrotoxin pretreatment.

\section{Effect of amphetamine on stimulated release}

We have demonstrated that amphetamine decreases stimulated release of dopamine in the caudate nucleus (Kuhr et al., 1985). This effect has been attributed to a depletion of vesicular dopamine, a known action of amphetamine. Amphetamine (1.0 $\mathrm{mg} / \mathrm{kg}, n=3$ ) does not significantly alter the stimulated release in the accumbens (Fig. 5), nor does it affect the rate of disappearance of dopamine after stimulated release. Administration of a larger dose $(10 \mathrm{mg} / \mathrm{kg}, n=3)$ does result in a slight diminution in release $30 \mathrm{~min}$ after drug administration $(78.9 \pm 2.7 \%$, $n=3, p<0.01$ ). However, if pargyline is given to an animal before the lower dose of amphetamine, a decrease in the stimulated release is observed in the accumbens ( $n=3$; Fig. 5).

Activity of MAO in the caudate nucleus and nucleus accumbens The ability of monoamine oxidase to deaminate benzylamine was assayed in these two brain regions. Both the $K_{\mathrm{m}}$ and the 
Figure 3. Effect of MAO inhibition of the stimulated release of dopamine in the nucleus accumbens and caudate nucleus of the rat. The release of dopamine was monitored in these regions as described in Figure 2. Each point represents the average magnitude of the maximum release for each stimulation, normalized to the average release before drug administration. Pargyline (75 $\mathrm{mg} / \mathrm{kg}$, i.p.) was administered at the time indicated by the arrow. The responses observed in the caudate nucleus (solid circles, $n=4$ ) and nucleus accumbens (open squares, $n=4$ ) are shown. Error bars, SEMs; *, significantly different from control, $p<0.05$, two-tailed Student's $t$ test.

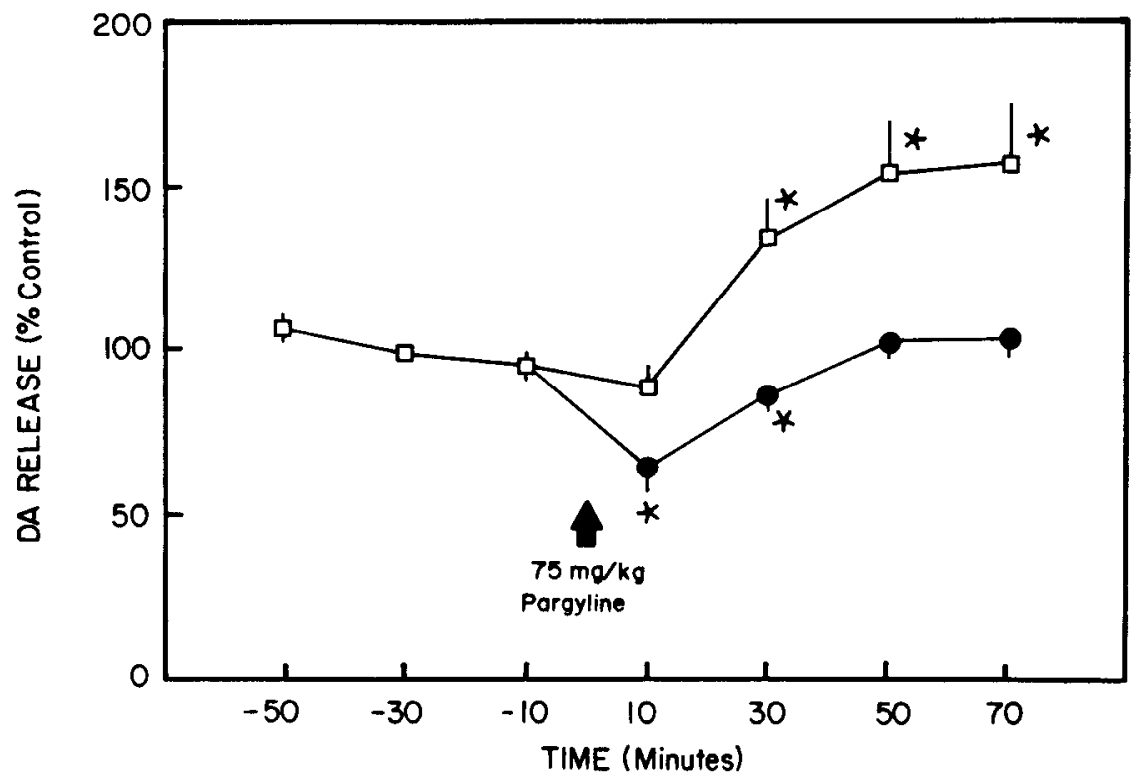

specific activity of MAO were found to be statistically identical in the two regions (Table 1).

\section{Discussion}

Electrical stimulation of the MFB, a major pathway for many neuronal systems (Nieuwenhuys et al., 1982; Veening et al., 1982), should excite dopaminergic fibers in the mesolimbic and nigrostriatal systems. It is not surprising, then, that dopamine release should occur following stimulation of these fibers. The only easily oxidized species that changes concentration in the nucleus accumbens and caudate nucleus during stimulation is identified to be a catecholamine by voltammetry. The voltammetry of catecholamines at these electrodes is sufficiently different from that observed for all other electroactive substances known to be in extracellular fluid (e.g., DOPAC, 3-methoxytyramine, HVA, uric acid, serotonin and its metabolites, and ascorbic acid), so we rule out the possibility that these compounds make a significant contribution to the observed signal (Kovach et al., 1984). Norepinephrine exhibits virtually identical voltammetry as dopamine (Kovach et al., 1984), but it

\begin{tabular}{|c|c|c|c|c|c|}
\hline Treatment & $n$ & $\mathrm{NE}$ & $\mathrm{DA}^{a}$ & DOPAC ${ }^{a}$ & HVA $^{a}$ \\
\hline \multicolumn{6}{|l|}{ Caudate nucleus } \\
\hline $\begin{array}{l}\text { Chloral hydrate } \\
(400 \mathrm{mg} / \mathrm{kg})\end{array}$ & 10 & $0.72 \pm 0.16$ & $105 \pm 6$ & $13.1 \pm 1.8$ & $9.8 \pm 1.0$ \\
\hline $\begin{array}{l}\text { Pargyline } \\
\qquad(75 \mathrm{mg} / \mathrm{kg}, 10 \mathrm{~min})^{b}\end{array}$ & 4 & - & $103 \pm 14$ & $12.3 \pm 1.5$ & $8.6 \pm 0.7$ \\
\hline $\begin{array}{l}\text { Pargyline } \\
\quad(75 \mathrm{mg} / \mathrm{kg}, 40 \mathrm{~min})^{b}\end{array}$ & 4 & - & $138 \pm 12^{c}$ & $0.9 \pm 0.1^{d}$ & $2.6 \pm 0.2^{d}$ \\
\hline Nonanesthetized & 4 & $0.58 \pm 0.21$ & $45 \pm 1^{d}$ & $13.8 \pm 0.6$ & $4.2 \pm 1.0^{d}$ \\
\hline $\begin{array}{l}\text { Pargyline } \\
\quad(75 \mathrm{mg} / \mathrm{kg}, 40 \mathrm{~min}, \text { nonanesthetized })\end{array}$ & 4 & - & $86 \pm 3^{e}$ & $1.3 \pm 0.2^{e}$ & $1.7 \pm 0.6^{e}$ \\
\hline \multicolumn{6}{|l|}{ Nucleus accumbens } \\
\hline $\begin{array}{l}\text { Chloral hydrate } \\
(400 \mathrm{mg} / \mathrm{kg})\end{array}$ & 10 & $6.8 \pm 1.9$ & $51 \pm 5$ & $10.0 \pm 1.3$ & $6.5 \pm 0.8$ \\
\hline $\begin{array}{l}\text { Pargyline } \\
\qquad(75 \mathrm{mg} / \mathrm{kg}, 10 \mathrm{~min})^{b}\end{array}$ & 4 & - & $75 \pm 6^{c}$ & $12.1 \pm 0.3$ & $7.9 \pm 0.6$ \\
\hline $\begin{array}{l}\text { Pargyline } \\
\qquad(75 \mathrm{mg} / \mathrm{kg}, 40 \mathrm{~min})^{b}\end{array}$ & 4 & - & $93 \pm 11^{d}$ & $0.8 \pm 0.2^{d}$ & $3.4 \pm 0.7^{c}$ \\
\hline Nonanesthetized & 4 & $6.2 \pm 1.6$ & $32 \pm 2^{c}$ & $13.4 \pm 0.8$ & $3.7 \pm 0.5^{c}$ \\
\hline $\begin{array}{l}\text { Pargyline } \\
\quad(75 \mathrm{mg} / \mathrm{kg}, 40 \mathrm{~min}, \text { nonanesthetized })\end{array}$ & 4 & - & $58 \pm 8^{e}$ & $2.3 \pm 0.5^{e}$ & $1.6 \pm 0.4$ \\
\hline
\end{tabular}

Amounts were determined by liquid chromatography with electrochemical detection.

${ }^{a} \mathrm{pmol} / \mathrm{mg}$ tissue $\pm \mathrm{SEM}$.

${ }^{b}$ Anesthetized with chloral hydrate $(400 \mathrm{mg} / \mathrm{kg})$.

' Different from control, $p<0.05$ (two-tailed Student's $t$ test).

${ }^{d}$ Different from control, $p<0.01$ (two-tailed Student's $t$ test).

' Different from non-anesthetized control, $p<0.01$ (two-tailed Student's $t$ test) 


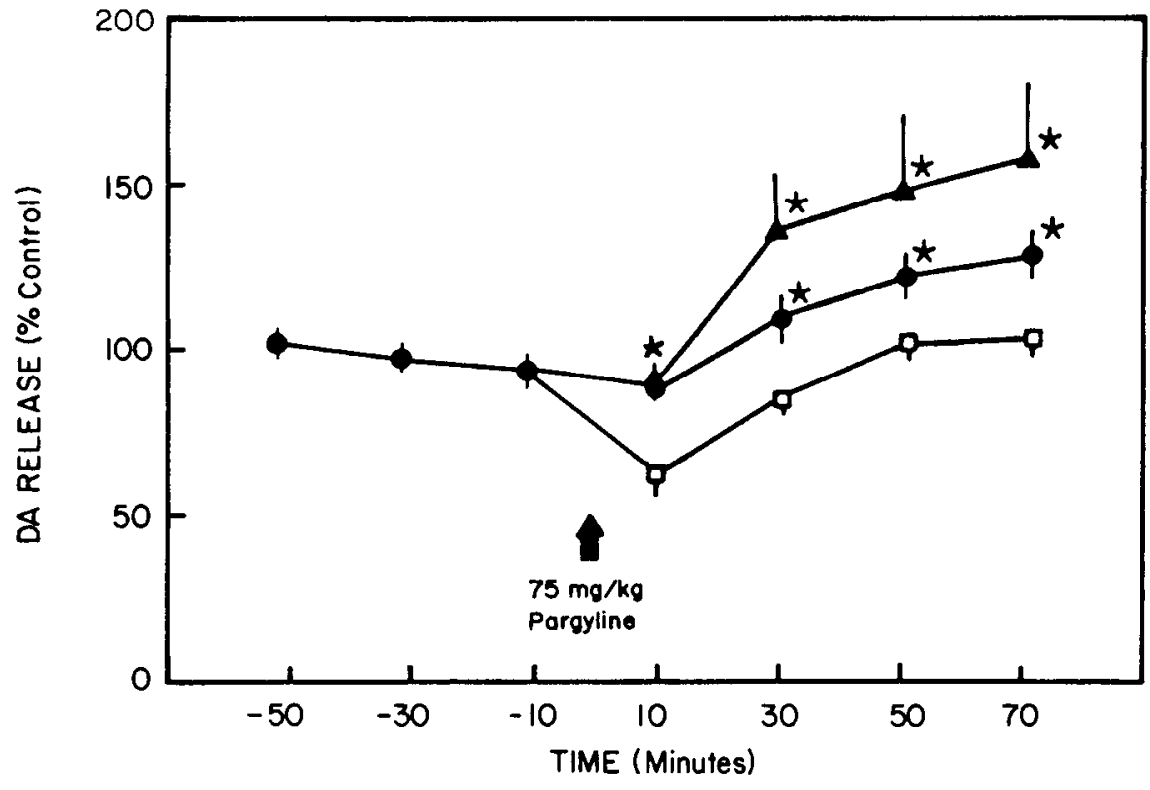

Figure 4. Blockade of the striatonigral feedback pathway alters the response of dopamine neurons in the caudate nucleus to the combined regimen of electrical stimulation and MAO inhibition. The evoked release of dopamine was monitored in the caudate nucleus as described in Figure 2. Pargyline $(75 \mathrm{mg} /$ $\mathrm{kg}$, i.p.) was administered at the time shown. The response of control animals (open squares, $n=6$ ), animals treated with picrotoxin $(1 \mathrm{mg} / \mathrm{kg}$, i.p., $1 \mathrm{hr}$ before the experiment was begun; closed circles, $n=4$ ) and crus ccrebri lesioned animals (solid triangles, $n=4$ ) are shown. Error bars, SEMs; *, signifcantly different from control; $p<0.05$, two-tailed Student's $t$ test. exists in the accumbens in amounts that are only $10 \%$ of that of dopamine (Versteeg et al., 1976; Table 2). Thus, while it may be present in the observed release, it is likely to be only a minor component of the accumbens' voltammogram. In support of this, we find that the release in the accumbens is unaffected by inhibition of norepinephrine synthesis. Furthermore, postmortem data after a single stimulation shows that the major change is in the amount of DOPAC, a dopamine metabolite. The voltammetric and postmortem data thus taken together indicate that the major species detected in vivo during stimulation is dopamine. In addition, anatomical, physiological, and pharmacological data provide strong supporting evidence for the assignment of dopamine.

The simultaneous measurements in two different brain regions permit the characterization of the differences and similarities of dopamine-stimulated release during the same stimulus. These measurements, however, are in an anesthetized preparation, and it has been shown that anesthesia can differentially affect catecholamine levels in different regions of the rat brain (McCown et al., 1983; Westerink et al., 1977). Fortunately, chloral hydrate anesthesia elevates catecholamine levels to the same extent in the caudate nucleus and the nucleus accumbens (Table 3 ).

The release of dopamine in the nucleus accumbens following medial forebrain stimulation shows many similarities with that previously observed in the caudate nucleus (Table 1). The stimulus parameters that have been investigated (frequency, current amplitude, and stimulus duration) all show a similar effect on the amplitude of release. This is consistent with the similarity of the electrophysiological properties of dopamine neurons originating from the ventral tegmental area and the substantia nigra (Grace and Bunney, 1984a, b; Wang, 1981a). Blockade of dopamine synthesis virtually abolishes the stimulated release of dopamine in both regions. Inhibition of conversion of tyrosine to 1-DOPA with $\alpha$-methyl-p-tyrosine, or inhibition of 1-DOPA to dopamine with NSD-1015, both result in the diminution of the dopamine available for release. Diminution of vesicular pools with reserpine leads to a similar decrease in evoked release in both regions. The use of the dopamine antagonist, haloperidol, results in a similar increase in stimulated release in both regions.

A portion of the dopamine stores in both regions is not readily available for release. This is perhaps most clearly demonstrated

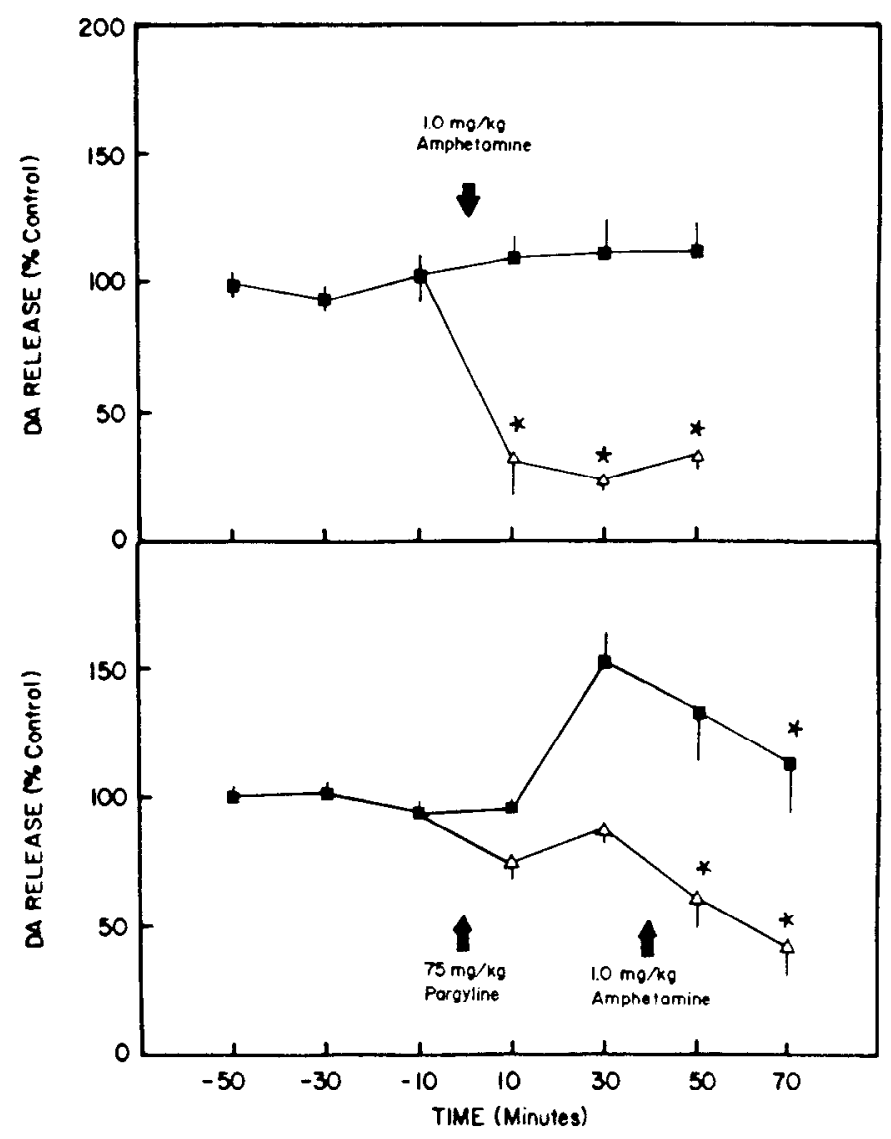

Figure 5. Effect of amphetamine on the stimulated release of dopamine in anesthetized rats (upper panel) or pargyline-treated anesthetized rats (lower panel). The evoked release of dopamine was induced as described in Figure 2. The responses observed in the caudate nucleus (open triangles) and nucleus accumbens (solid squares) are shown. Average values are as described in Figure $3 ;{ }^{*}$, significantly different from control; $p<0.05$, two-tailed Student's $t$ test. Upper panel, Amphetamine (1.0 $\mathrm{mg} / \mathrm{kg}$ ) was administered at the time indicated $(n=4)$. Lower panel, Pargyline $(75 \mathrm{mg} / \mathrm{kg}$, i.p.) and amphetamine $(1 \mathrm{mg} / \mathrm{kg}$, i.p.) were administered at the time indicated $(n=4)$. 
by postmortem analysis following repetitive stimulation. After the administration of a synthesis inhibitor (in this case, NSD1015), the evoked release of dopamine is virtually eliminated by the fourth stimulation after drug administration, even though almost half of the tissue stores of dopamine still exist. This is unlikely to be a reflection of a partial activation of dopamine fibers because release can be temporarily re-established after administration of amfonelic acid. Postmortem analysis after a single stimulation also supports the concept of a restricted pool available for release. The fraction of dopamine converted to DOPAC as a result of a single supramaximal stimulation is only a small portion of the total stores. In addition, the amount of dopamine observed during a stimulation can be calculated to be in close agreement with the amount of DOPAC formed (Kuhr et al., 1984).

Thus data collected from both regions are consistent with the concept that there exists a functional and nonfunctional pool of dopamine (Javoy and Glowinski, 1971; de Langen et al., 1979). However, there have been few reports as to the factors that regulate this pool. Since synthesis of dopamine is believed to be a cytoplasmic process, we reasoned that MAO, which is found in mitochondria in the cytoplasm of dopamine neurons (Urwyler and von Wartberg, 1980), might exert a regulatory effect on the sizc of the pool. Inhibition of MAO with pargyline results in an increase in stimulated dopamine release in the nucleus accumbens, but has little effect on caudate release (Fig. 3; Kuhr et al., 1984; Millar et al., 1985).

The role of MAO in the regulation of dopamine levels has been examined previously (for a review, see Westerink, 1979). Several investigators have demonstrated that two forms of MAO exist (Kim and D'Iorio, 1968; Youdim et al., 1979), distinguished primarily on the basis of their substrate specificity and their differential inhibition sensitivity (Harsing and Vizi, 1984; Schoepp and Azzaro, 1981a, b, 1982). The primary form of MAO found in dopamine nerve terminals is Type A (Urwyler and von Wartburg, 1980). There is considerable evidence that the MAO activity found inside nerve terminals is only a small fraction of the total MAO activity of the striatum (Francis et al., 1985; Marsden et al., 1972; Schoepp and Azzaro, 1983; Uretsky and Iversen, 1970; Van der Krogt et al., 1983). Our measurements show that the activity of MAO B is similar in each brain region. Nevertheless, the small fraction of the total $\mathrm{MAO}$ in nerve terminals could play a large role in regulating dopamine functional levels because of the close proximity of this MAO to newly synthesized dopamine.

Evidence in support of this hypothesis comes from comparison of DOPAC tissue levels. The same level of DOPAC is found in the caudate nucleus and nucleus accumbens under normal conditions (Speciale et al., 1980; Westerink and Korf, 1976a, b; Westerink et al., 1977, 1984), while dopamine levels are twice as large in the caudate as in the accumbens (Table 2; Rosen et al., 1984; van Heuven-Nolsen et al., 1983; Waldemeier and Maitre, 1976). Thus, the rate of DOPAC formation must be greater in the accumbens. Since the turnover rate for dopamine in these tissues is virtually the same (Waldemeier and Maitre, 1976; Westerink and Korf, 1976a), this implies greater regulation of dopamine levels by MAO in the accumbens. Further evidence is provided by measurements of DA striatal levels after pargyline. DA levels are more greatly elevated in mesolimbic tissue than in the striatum in both anesthetized and nonanesthetized animals (Table 3; Fadda et al., 1977; Umeza and Moore, 1979; Westerink and Spaan, 1982; Westerink et al., 1984).

Lesions of the crus cerebri did not alter the concentration of dopamine released by electrical stimulation in the caudate nucleus; however, an increase in evoked release was observed after administration of pargyline. From this result we conclude that MAO is capable of regulating the amount of stimulated dopamine release in the caudate nucleus in the same manner as observed in the nucleus accumbens. But this regulation is only apparent with our experimental protocol after removal of the negative feedback pathway. This model is also consistent with data obtained by Di Chiara et al. (1977), who found that DOPAC levels doubled in the caudate nucleus after a kainic acid lesion of the striatum, without a corresponding change in dopamine levels.

It thus appears that the size of the functional pool in the caudate nucleus is under more direct control by the striatonigral pathway than the actions of intracellular MAO. To test for GABA regulation either in the nigra (Ladinsky et al., 1976) or in the caudate (Scatton and Bartholini, 1980), picrotoxin was given prior to pargyline administration. This GABA antagonist facilitates an increase in dopamine-stimulated release induced by pargyline in the caudate nucleus without altering the effect of pargyline in the nucleus accumbens. Control of dopamine release by GABA has been previously demonstrated in the caudate nucleus. GABA increases the electrically stimulated release of dopamine in rat striatal slices under certain conditions (Riemann et al., 1982). GABA also has been shown to increase the spontaneous release of dopamine in the caudate nucleus (Giorguieff et al., 1978). The actions of GABA in these experiments were thought to involve interneurons, since the effects were blocked by tetrodotoxin and are not observed in synaptosomes (Caudill et al., 1985).

Further evidence for the different regulation of dopamine pools comes from the experiments with amphetamine. Amphetamine causes a decrease of the stimulated release in the caudate nucleus, in accord with its identificd ability to displace dopamine from vesicles (Kuhr et al., 1985). However, this effect is not apparent in the nucleus accumbens unless MAO is previously inhibited with pargyline. Amphetamine is an inhibitor of MAO, in addition to its actions on vesicular storage of dopamine (Clarke et al., 1979). Therefore, its lack of an effect on stimulated release in the accumbens may result from its opposing actions on the releasable pool in this region - an enhancement of the releasable pool, as was observed with pargyline, and an offsetting effect on the vesicular storage, as has been observed with reserpine. In the caudate nucleus, where regulation of the releasable pool of dopamine by MAO is not so evident, the depletion of releasable dopamine by amphetamine is more clearly observed.

\section{Conclusions}

In vivo voltametry provides a unique method to monitor stimulated dopamine release. The amount of stimulated release is a reflection of dopamine available for release. The factors that regulate this pool are different in the nucleus accumbens and the caudate nucleus. The releasable pool in the accumbens is regulated by MAO. Regulation of the functional pool by MAO in the caudate nucleus is only apparent after lesions of the striatonigral pathway. Therefore, it appears that regulation of pool size in the caudate nucleus normally is connected with this feedback loop. These differences in regulatory mechanisms in the nucleus accumbens and the caudate nucleus may help to explain some of the differential actions of pharmacological agents in these brain regions.

\section{References}

Bouyer, J. J., T. H. Joh, and V. M. Pickel (1984) Ultrastructural localization of tyrosine hydroxylase in rat nucleus accumbens. J. Comp. Neurol. 227: 93-103.

Caudill, W. L., J. C. Bigelow, and R. M. Wightman (1985) Comparison of release of dopamine and $\gamma$-aminobutyric acid from rat caudate synaptosomes. Neurochem. Res. 10:319-331.

Clarke, D. E., H. H. Miller, and P. A. Shore (1979) Monoamine oxidase inhibition by $(+)$ amphetamine in vivo. Br. J. Pharmacol. $66: 435 \mathrm{P}-$ 436P.

de Langen, C. D. J., J. C. Stoof, and A. H. Mulder (1979) Studies on the nature of the releasable pool of dopamine in synaptosomes from 
rat corpus striatum: Depolarization-induced release of ${ }^{3} \mathrm{H}$-dopamine from superfused synaptosomes labelled under various conditions. Naunyn Schmiedebergs Arch. Pharmakol. 308: 41-49.

Di Chiara, G., M. L. Porceddu, W. Fratta, and G. L. Gessa (1977) Post-synaptic receptors are not essential for dopaminergic feedback regulation. Nature 267: 270-272.

Ewing, A. G., and R. M. Wightman (1984) Monitoring the stimulated release of dopamine with in vivo voltammetry II: Clearance of released dopamine from extracellular fluid. J. Neurochem. 43: 570-577.

Ewing, A. G., M. A. Dayton, and R. M. Wightman (1981) Pulse voltammetry with microvoltammetric electrodes. Anal. Chem. 53: 1842-1847.

Ewing, A. G., R. M. Wightman, and M. A. Dayton (1982) In vivo voltammetry with electrodes that discriminate between dopamine and ascorbate. Brain Res. 249: 361-370.

Ewing, A. G., J. C. Bigelow, and R. M. Wightman (1983) Direct in vivo monitoring of dopamine released from two striatal compartments. Science 221: 169-170.

Fadda, F., A. Argiolas, E. Stefanini, and G. L. Gessa (1977) Differential effect of psychotropic drugs on dihydroxyphenylacetic acid in the rat substantia nigra and caudate nucleus. Life Sci. 21: 411-418.

Fekete, M. I. K., J. P. Herman, B. Kanyicska, and M. Palkovits (1979) Dopamine, noradrenaline and 3,4-dihydroxyphenylacetic acid levels of individual brain nuclei, effects of haloperidol and pargyline. $J$. Neural Trans. 45: 207-218.

Francis, A., B. Pearce, and J. A. Roth (1985) Cellular localization of MAO A and B in brain: Evidence from kainic acid lesions in striatum. Brain Res. 334: 59-64.

Giorguieff, M. F., M. L. Kemel, J. Glowinski, and M. J. Beson (1978) Stimulation of dopamine release by GABA in rat striatal slices. Brain Res. 139: 115-130.

Grace, A. A., and B. S. Bunney (1984a) The control of firing pattern in nigral dopamine neurons: Single spike firing. J. Neurosci. 4: 28662876.

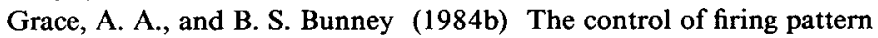
in nigral dopamine neurons: Burst firing. J. Neurosci. 4: 2877-2890.

Harsing, L. G., and E. S. Vizi (1984) Release of endogenous dopamine from rat isolated striatum: Effect of clorgyline and (-)deprenyl. $\mathrm{Br}$. J. Pharmacol. 83: 741-749.

Horn, A. S., A. C. Cuello, and R. J. Miller (1974) Dopamine in the mesolimbic system of the rat brain: Endogenous levels and the effects of drugs on the uptake mechanism and stimulation of adenylate cyclase activity. J. Neurochem. 22: 265-270.

Hunt, P., J.-P. Raynaud, M. Leven, and U. Schacht (1979) Dopamine uptake inhibitors and releasing agents differentiated by the use of synaptosomes and field-stimulated brain slices in vitro. Biochem. Pharmacol. 28: 2011-2016.

Javoy, F., and J. A. Glowinski (1971) Dynamic characteristics of the "functional compartment" of dopamine in dopaminergic terminals of the rat striatum. J. Neurochem. 18: 1305-1311.

Javoy, F., Y. Agid, D. Bouvet, and J. A. Glowinski (1972) Feedback control of dopamine synthesis in dopaminergic terminals of the rat striatum. J. Pharmacol. Exp. Ther. 182: 454-463.

Kelly, P. H., and K. E. Moore (1976) Mesolimbic dopaminergic neurons in the rotational model of nigrostriatal function. Nature 263: 695-696.

Kim, J. S., and A. D'Iorio (1968) Possible isoenzymes of monoamine oxidase in rat tissues. Can. J. Biochem. 46: 295-297.

Korf, J. (1979) Electrical stimulation as a tool for the study of biochemical aspects of dopamine neurotransmission. In Neurobiology of Dopamine, A. S. Horn, J. Korf, and B. H. C. Westerink, eds., pp. 237-253, Academic, London.

Kovach, P. M., A. G. Ewing, R. L. Wilson, and R. M. Wightman (1984) In vitro comparison of the selectivity of electrodes used for in vivo electrochemistry. J. Neurosci. Meth. 10: 215-227.

Kuhr, W. G., A. G. Ewing, W. L. Caudill, and R. M. Wightman (1984) Monitoring the stimulated release of dopamine with in vivo voltammetry I: Characterization of the response observed in the caudate nucleus of the rat. J. Neurochem. 43: 560-569.

Kuhr, W. G., A. G. Ewing, J. A. Near, and R. M. Wightman (1985) Amphetamine attenuates the stimulated release of dopamine in vivo. J. Pharmacol. Exp. Ther. 232: 388-394.

Ladinsky, H., S. Consolo, S. Bianchi, and A. Jori (1976) Increase in striatal acetylcholine by picrotoxin in the rat: Evidence for a gabaergicdopaminergic-cholinergic link. Brain Res. 108: 351-361.

Marsden, C. A., O. J. Broch, and H. C. Guldberg (1972) Effect of nigral and raphe lesions on the catechol-o-methyl transferase and monoamine oxidase activities in the rat striatum. Eur. J. Pharmacol. 19: $35-42$.

McCown, T. J., R. A. Meuller, and G. R. Breese (1983) Effects of anesthetics and electrical stimulation on nigrostriatal dopaminergic neurons. J. Pharmacol. Exp. Ther. 224: 489-493.

Millar, J., J. A. Stamford, Z. L. Kruk, and R. M. Wightman (1985) Electrochemical, pharmacological, and electrophysiological evidence of rapid dopamine release and removal in the rat caudate nucleus following electrical stimulation of the median forebrain bundle. Eur. J. Pharmacol. 109: 341-348.

Mogenson, G. J., and C. Y. Yin (1981) Electrophysiological and neuropharmacological-behavioral studies of the nucleus accumbens: Implications for its role as a limbic-motor interface. In The Neurobiology of the Nucleus Accumbens, R. B. Chronister and J. F. DeFrance, eds., pp. 210-229, Haer Institute for Electrophysiological Research, Sebasco Estates, ME.

Nieuwenhuys, R., L. M. G. Geeraedts, and J. G. Veening (1982) The medial forebrain bundle of the rat. I. General introduction. J. Comp. Neurol. 206: 49-81.

Nissinen, E. (1984) Determination of monoamine oxidase B activity by high performance liquid chromatography. J. Chromatogr. 309: 156-159.

Pelligrino, L. J., and A. J. Cushman (1967) A Stereotaxic Atlas of the Rat Brain, Appleton-Century-Crofts, New York.

Pycock, C. J., and C. J. Marsden (1978) The rotating rodent: A two component system? Eur. J. Pharmacol. 47: 165-175.

Rebec, G. V., and K. S. Zimmerman (1980) Opposite effects of $d$-amphetamine on spontaneous neuronal activity in the neostriatum and nucleus accumbens. Brain Res. 201: 485-491.

Reimann, W., A. Zumstein, and K. Starke (1982) $\gamma$-Aminobutyric acid can both inhibit and facilitate dopamine release in the caudate nucleus of the rabbit. J. Neurochem. 39: 961-969.

Reynolds, G. P., P. Riederer, K. Jellinger, and E. Gabriel (1981) Dopamine receptors and schizophrenia: The neuroleptic drug problem. Neuropharmacology 20: 1319-1320.

Rosen, G. D., S. Finklestein, A. L. Stoll, D. A. Yutzey, and V. H. Denenberg (1984) Neurochemical asymmetries in the albino rat's cortex, striatum and nucleus accumbens. Life Sci. 34: 1143-1148.

Scatton, B., and G. Bartholini (1980) Modulation by GABA of cholinergic transmission in the striatum. Brain Res. 183: 211-216.

Scherman, D., and J. P. Henry (1980) Effect of drugs on the ATPinduced and $\mathrm{pH}$-gradient driven membrane transport by bovine chromaffin granules. Biochem. Pharmacol. 29: 1883-1890.

Schoepp, D. D., and A. J. Azzaro (1981a) Specificity of endogenous substrates for types $A$ and $B$ monoamine oxidase in rat striatum. $J$. Neurochem. 36: 2025-2031.

Schoepp, D. D., and A. J. Azzaro (1981b) Alteration of dopamine synthesis in rat striatum subsequent to selective type A monoamine oxidase inhibition. J. Neurochem. 37: 527-530.

Schoepp, D. D., and A. J. Azzaro (1982) Role of type A and type B monoamine oxidase in the metabolism of released $\left[\mathrm{H}^{3}\right]$ dopamine from rat striatal slices. Biochem. Pharmacol. 31: 2961-2968.

Schoepp, D. D., and A. J. Azzaro (1983) Effects of intrastriatal kainic acid injection on $\left[{ }^{3} \mathrm{H}\right]$ dopamine metabolism in rat striatal slices: Evidence for postsynaptic glial cell metabolism by both the type $A$ and B forms of monoamine oxidase. J. Neurochem. 40: 1340-1348.

Speciale, S. G., F. Karoum, and R. J. Wyatt (1980) Different effects of amphetamine and amfonelic acid on peripheral and central catecholamine metabolism. Eur. J. Pharmacol. 62: 297-307.

Stamford, J. A., Z. L. Kruk, J. Millar, and R. M. Wightman (1985) Striatal dopamine uptake: In vivo analysis by fast cyclic voltammetry. Neurosci. Lett. 51: 133-138.

Tulloch, I. F., G. W. Arbuthnott, A. K. Wright, M. Garcia-Munoz, and N. M. Nicolaou (1978) The striatonigral fibers and the feedback control of dopamine metabolism. Psychol. Med. 8: 471-482.

Umeza, K., and K. E. Moore (1979) Effects of drugs on regional brain concentrations of dopamine and dihydroxyphenylacetic acid. J. Pharmacol. Exp. Ther. 208: 49-56.

Uretsky, N. J., and L. L. Iversen (1970) Effects of 6-hydroxydopamine on catecholamine containing neurons in the rat brain. J. Neurochem. 17: 269-278.

Urwyler, S., and J.-P. von Wartburg (1980) Studies on the subcellular localization of monoamaine oxidase types $A$ and $B$ and its importance in the deamination of dopamine in the rat brain. Biochem. Pharmacol. 29: 3067-3073. 
van der Heyden, J. A. M. (1984) Circling behavior induced by electrical stimulation of the medial forebrain bundle, importance of stimulus parameters and dopaminergic processes. Pharmacol. Biochem. Behav. 21: 567-574.

Van der Krogt, J. A., E. Koot-Gronsveld, and C. J. Van der Berg (1983) Localization of rat striatal monoamine oxidase activities toward dopamine, serotonin and kynuramine by gradient centrifugation and nigro-striatal lesions. Life Sci. 33: 615-623.

van Heuven-Nolsen, D., L. van Wolfswinkel, J. M. van Ree, and D. H. G. Versteeg (1983) Electrical stimulation of the ventral tegmental area and catecholamine metabolism in discrete regions of the rat brain. Brain Res. 268: 362-366.

Veening, J. G., L. W. Swanson, W. M. Cowan, R. Nieuwenhuys, and L. M. G. Geeraedts (1982) The medial forebrain bundle of the rat. II. An autoradiographic study of the topography of the major descending and ascending components. J. Comp. Neurol. 206: 82-108.

Versteeg, D. H. G., J. Van der Gusten, W. De Jong, and M. Palkovits (1976) Regional concentrations of noradrenaline and dopamine in the rat brain. Brain Res. 113: 563-574.

Waldemeier, P. C., and L. Maitre (1976) On the relevance of preferential increases of mesolimbic versus striatal dopamine turnover for the prediction of antipsychotic activity of psychotropic drugs. $\mathbf{J}$. Neurochem. 27: 589-597.

Wang, R. (1981a) Dopaminergic neurons in the rat ventral tegmental area I. Identification and characterization. Brain Res. Rev. 3: 123140.

Wang, R. (1981b) Dopaminergic neurons in the rat ventral tegmental area II. Evidence for autoregulation. Brain Res. Rev. 3: 141-151.

Westerink, B. H. C. (1979) Effects of drugs on dopamine biosynthesis and metabolism in the brain. In Neurobiology of Dopamine, A. S. Horn, J. Korf, and B. H. C. Westerink, eds., pp. 255-291, Academic, London.

Westerink, B. H. C., and J. Korf (1976a) Turnover of acid dopamine metabolites in striatal and mesolimbic tissue of the rat brain. Eur. J. Pharmacol. 37: 249-255.

Westerink, B. H. C., and J. Korf (1976b) Regional brain levels of 3,4dihydroxyphenylacetic acid and homovanillic acid: Concurrent fluorometric measurement and influence of drugs. Eur. J. Pharmacol. 38 . 281-291.

Westerink, B. H. C., and S. J. Spaan (1982) Simultaneous determination of the formation rate of dopamine and its metabolite 3,4dihydroxyphenylacetic acid in various rat brain areas. Brain Res. 252: 239-245.

Westerink, B. H. C., B. Lejeune, J. Korf, and H. M. Van Praag (1977) On the significance of regional dopamine metabolism in the rat brain for the classification of centrally acting drugs. Eur. J. Pharmacol. 42: 179-190.

Westerink, B. H. C., F. J. Bosker, and E. Wirix (1984) Formation and metabolism of dopamine in nine areas of the rat brain: Modification by haloperidol. J. Neurochem. 42: 1321-1327.

White, F. J., and R. Y. Wang (1982) Differential effects of classical and atypical antipsychotic drugs on $A 9$ and $A 10$ dopamine neurons. Science 221: 1054-1056.

Wilkinson, G. N. (1961) Statistical estimations in enzyme kinetics. Biochem. J. 80: 324-332.

Youdim, M. B. H., G. G. S. Collins, and M. Sandler (1969) Multiple forms of rat brain monoamine oxidase. Nature 223: 626-628. 